\title{
The general practitioner and the problems of battered women
}

\author{
Jan Pahl Research Fellow, University of Kent
}

\section{Author's abstract}

This paper discusses the responsibility of general practitioners who are consulted by women who have been physically injured by the men with whom they live. The paper draws on a study of 50 women who were interviewed at a refuge for battered women, and considers the help which they received, or did not receive, from their general practitioners. Such women are likely to face many difficulties: $i$ it is perhaps the essence of their problem that, because it is potentially the concern of so many people, it can so easily become the concern of nobody-except of the woman herself.

It has long been recognised that a general practitioner will inevitably be concerned with more than just the physical health of his or her patients. On the one hand there is the awareness among general practitioners that symptoms of physical or mental ill health may be closely related to wider social problems such as poverty, bad housing, marital discord, or family difficulties of one sort and another; on the other hand, there is often an expectation among patients that the doctor may be able to offer advice, if not concrete help, with such problems.

This wider definition of the general practitioner's role has been spelled out in a number of different statements. For example, in 1972 the Royal College of General Practitioners ${ }^{1}$ stated that 'the general practitioner is a doctor who provides personal, primary and continuing medical care to individuals and families. He accepts the responsibility for making an initial decision on every problem his patient may present to him, consulting with specialists when he thinks it appropriate to so so. ... His diagnoses will be composed in physical, social and psychological terms. He will intervene educationally, preventively and therapeutically to promote his patients' health.'

In 1973 the Royal College of General Practitioners $^{2}$ suggested that one of the special features and characteristics of general practice is that the 'field of work will be illnesses and social problems that might be expected to occur in a population of about 2,500 persons.'

Attempts have been made to estimate the extent to which such social problems might be expected to occur in the 'average' practice, and a summary of $\stackrel{\mathbb{Q}}{\unrhd}$ these estimates was presented by the Royal College is of General Practitioners. ${ }^{2}$ It was suggested that in $\vec{\circ}$ an average population of 2,500 there would be likely to be about 150 households living on supple- $\vec{\omega}$ mentary benefit, 60 one-parent families, 25 ? alcoholics, and 3-4 divorces in any one year. Such $\underset{\oplus}{\widehat{D}}$ estimates, of course, take no account of variations ir from place to place, nor over time: the I970s have $\omega$ seen a great increase in the numbers of households $\vec{\nabla}$ living on supplementary benefit, and in the numbers $O$ of divorces and, consequently, of one parent families. ${ }^{3}$ Jefferys estimated that $36 \cdot 4$ per cent of all $\vec{c}$ those consulting their general practitioners did so $\mathbb{D}$ partly on account of social problems. ${ }^{4}$ Ratoff and $\mathbb{D}$ Pearson, discussing the relative frequency with $\bar{\partial}$ which different problems are brought to general practitioners, suggested that the most common such $\vec{\omega}$ problem was poverty (3I per cent of all socif है problems) followed by marital problems (29 pe cent) and housing problems ( 17 per cent). ${ }^{5}$

Faced with such statistics it would be understandable if the average general practitioner were to feel swamped by the extent of his or her $\frac{2}{0}$ responsibilities. What are the limits of the doctor's $\varnothing$ responsibility for the patient? Where should the $\overrightarrow{\overrightarrow{0}}$ boundary lines be set between the responsibilities 3 of the general practitioner and those of other professionals? To what extent should the doctor accept the patient's definition of what is wrong? Studies of client evaluation of the help offered by social workers show that much client dissatisfaction arises out of the failure of social workers to offer the sort of help that the client expects them to provide. $^{6,7}$ To what extent do similar misunderstandings occur in the doctor's consulting room?

This paper aims to discuss these general questions $\frac{D}{O}$ in the light of a study which was specifically concerned with the problems of battered women. ${ }^{8}$ o Such women may have physical symptoms, such as cuts, bruises, fractures and internal injuries, and so 0 it would be quite appropriate that they should $\omega$ consult a general practitioner; however, in most cases, neither the causes of the problem nor its long-term solutions will have been covered in the $\mathbb{D}$ course of the general practitioner's medical training. Because of their physical injuries battered women 0 will continue to go to the doctor for help, yet $\frac{P}{\mathbb{D}}$ without considering the problem in its wider $\stackrel{?}{+}$ context, and without being aware of a wide range $\stackrel{\unrhd}{\varnothing}$ 
of non-medical solutions, general practitioners are likely to have little real help to offer. It is in this context that the question arises: What should be the limits of a general practitioner's responsibility in such cases ?

\section{The problem of battered women}

Before considering the findings of my own research work, there are some general points which must be made about this problem. First, it is important to stress that the violence suffered by most of the women is not trivial. The Royal College of Psychiatrists defined a battered wife as 'a woman who has suffered serious or repeated physical injury from the man with whom she lives.' The seriousness of the assaults can be illustrated by listing some of the injuries which had been suffered by the women whom I interviewed: these included black eyes, broken arms, noses and ribs, stab wounds, a ruptured spleen, severe bruising and a wide range of cuts bad enough to need stitching. These are the sort of injuries which, if they were inflicted in the street, and particularly if they were inflicted by someone who was a stranger to his victim, would be likely to be dealt with under the Offences Against the Person Act of 186r. Thus if there is to be a special category called 'battered women' it is not the nature of the injury which is the basis of the categorisation, but rather the relationship between the two people concerned.

So, secondly, this problem cannot be understood without taking into account the relationship within which it occurs. The words 'battered woman' are a reminder that some women are battered, not by a husband, but by a boyfriend, or, in some of the most intractable cases, by an ex-husband. ${ }^{9.10}$ The words 'battered wife' are a reminder that an important aspect of the problem is that the woman is likely to be in some way dependent on the man, that she is either married to him, or is living with him in a marriage-like relationship, that they may have children in common, and are likely to share a home. Certainly many women see the violence as taking place in a context of disagreement about the nature of the relationship. Many wives described how their husbands would attempt to dominate and subdue them, would ask them to wake up and cook meals in the middle of the night, would fly into a rage because the children were served first or would forbid family and friends to call at the house. Some of the women were kept extremely short of money, and it seemed as though control of the money was used by many husbands to control the wife's area of autonomy. ${ }^{11}$ Many of the men seemed to seek trivial ways in which to humiliate their wives so that their dominance within the marriage should be in no doubt, and to fall back on violence as a way of maintaining authority when other sources of power proved inadequate, ${ }^{12,13}$ Conversely, when the woman approached official agencies for help, the $\frac{c}{\bar{c}}$ nature of her relationship with the man whoo assaulted her was likely to be a crucial determinant of the sort of help she could expect to be offered. ${ }^{14}$

A third important aspect of this problem is that ${ }^{\text {? }}$. the assaults usually take place in the privacy of the home. This means that it is much easier to conceal the crime of wife assault than that of assault in the street. The Dobashes, in their study of 3,020 offences $\overline{\bar{n}}$ involving violence which were recorded by the police in Glasgow and Edinburgh in 1974, showed that while violence between unrelated maleses constituted the largest category $(38 \cdot 7$ per cent), the $\overrightarrow{0}$ second most frequent offence was violence by husbands directed at their wives (26 per cent).. However, they estimated that only two out of every 98 wife assaults was reported to the police. ${ }^{15}$ Such evidence as there is suggests that the incidence of violent marriages is between I per cent and 5 per cent, with another 15 per cent of marriages in $\vec{V}$ which some violence does occur, but only rarely..$^{16} \mathrm{O}$ These percentages are, however, extremely tentative, and the Select Committee on Violence in Marriagecs was forced to conclude that 'despite all our efforts we are unable to give any estimates of what the likely, numbers are; several witnesses talked to us ino terms of the tip of an iceberg and this seems to us ${ }^{\circ}$ to be correct. Most witnesses agreed (and this isce almost certainly correct) that all strata of society involved although the better off are perhaps les $S$ likely to seek outside help in solving the problems.' 17

Some measure of the extent of the problem can bea obtained from looking at the phenomenal growth of women's refuges in Britain. From the setting up of the first refuge in 1971 the number has grown soO that today there are over 140 refuges, most of which are affiliated to the National Women's Aid Federa $-\frac{7}{0}$ tion. The refuges provide safe accommodation for women who have been physically battered or mentally harassed, and try to make available to them whatever support, advice and help they feel 3 . they need. No time limits are set on the length of stay so a woman and her children can remain at the 3 refuge for as long as she feels it necessary. ${ }^{18}$

However, by the time a woman considers leaving? home and going to a refuge the violence willo normally have been going on for many years. $A$ woman who is being assaulted by the man with $N$ whom she lives will often try to conceal what is $N$ happening, sometimes because she feels ashamed of 'her' failure to achieve a 'normal' married relation- $\omega$ ship, sometimes because she wishes to protect the man who is ill-treating her, sometimes because she thinks that it will be better for the children if the family stays together. When she decides to involve others in her problems there are, broadly, two stages ${ }_{0}^{-}$ in help-seeking. During the first stage the woman $\mathbb{D}$ remains at home: she may ask her mother's advice, $\stackrel{\overrightarrow{\mathrm{C}}}{\mathrm{O}}$ borrow money from her family, call in the police for 
protection, go to a doctor about her injuries, consult a lawyer about possible legal proceedings, or discuss what is going on with her health visitor or social worker. The second and more drastic stage comes when she feels she must leave home, usually taking the children, and find other accommodation: this accommodation may be with friends or relatives, it may be in a rented room, in a Women's Aid refuge, or in temporary accommodation provided by the Housing Department.

A number of different, and apparently contradictory explanations have been put forward to account for the assault of wives by their husbands. One approach sees the problem as an individual one, and as being related to the personal inadequacies of the individuals concerned. It has sometimes been suggested in the popular press that battered women are by nature masochists; no researcher who has investigated the subject has found any support for this hypothesis. However, some researchers have suggested that the cause should be sought in the inadequacies of the violent husband. The study by Faulk of men who had been convicted of wife assault suggested that a majority of the sample could be classified as mentally ill in one way or another. ${ }^{19}$ However, other studies have not confirmed this suggestion and it must be remembered that those who are convicted of this crime are a tiny, and probably unrepresentative, proportion of the total population of men who assault their wives. Some researchers have found a link between violence and alcohol: in my own study just under half of the men were said by their wives to be heavy drinkers, and this proportion is similar to that found by Gelles in his study of The Violent Home. ${ }^{20}$ Gelles concludes his study with an explanation of the problem in terms of learned behaviour and suggests that the role models presented to an individual in his childhood socialise him into an acceptance of violence as a way of dealing with stress, frustration, or threats to personal identity. The difficulty with this hypothesis is that we do not know how many men who grew up in violent homes do not, as adults treat their wives violently.

A second approach sees the problem as being essentially a family problem and provides explanations not in terms of the individual but in terms of the family. Sometimes the family in which battering occurs is seen as being mal-functioning, as lacking a 'code of communication' ${ }^{21}$ The study which was done by the NSPCC explained the problem in these terms, and the NSPCC has now set up a unit to provide therapy sessions for couples between whom there has been violence. Gayford, who has completed a study of 100 women who stayed at the Chiswick refuge, has described the women who come to the refuge as being likely to have had early sexual experience, to have used inadequate contraceptive methods and to have had to marry young because of the imminent birth of a baby. ${ }^{22}$ The
Select Committee Report on Violence in Marriage $\frac{c}{3}$ saw the causes of marital violence as related to $\stackrel{\mathbb{Q}}{\complement}$ these sorts of family inadequacies and said of the $m$ available evidence that 'it suggests very clearly that those women who marry (and become pregnant) very young and after short or non-existent periods of $\overrightarrow{\vec{B}}$ courtship are particularly at risk, that drinking of $\frac{0}{0}$ alcohol may well trigger off or accentuate violence, and that children living in an environment of $\frac{\bar{\omega}}{\bar{N}}$ domestic violence may be predisposed to violence $\frac{\vec{\sigma}}{\sigma}$ in their own adult lives.' 17 Another analysis of the $\Omega$ problem which explains violence in terms of the $\%$ family is that put forward by Goode, who sees $\vec{\circ}$ violence as a source of power and as one which is likely to be used when other sources of power are $\vec{\omega}$ not available. Thus a husband who feels inadequate -perhaps because he is unemployed-may resort $\overparen{\Phi}$ to violence in an attempt to remain dominant within or the family, in a situation in which his status is $\omega$ threatened; in sociological terms, he tries to bridge $\vec{\nabla}$ the gap between his ascribed status (as head of the $\mathrm{O}$ household) and his achieved status (as a low-paid or unemployed worker who is in fact unable to behave $\vec{i}$ as he feels the head of the household should be able $\mathbb{D}$ to behave) by using violence. ${ }^{23}$

A third approach, however, explains the problem at a more fundamental level and sets in a wider $\stackrel{\mathbb{D}}{?}$ context those analyses which explain wife assault $\vec{\varphi}$ in terms of individual inadequacy or famil mal-functioning. This approach sees the problem as one consequence of women's position in the sociel. structure; it focuses attention on the dependent position of the wife in marriage and on the structural and ideological forces in the wider society which tend to lock women into marriage and into specific roles within the family. ${ }^{24}$ This explanation would look beyond the connection between drinking and violence to ask why it is that a wife appears as the 'appropriate victim' for such violence and why it is that if a drunk man hits another man the police are likely to call it an assault, while if he hits his wife $\stackrel{\Phi}{\square}$ they are likely to call it a 'domestic dispute' and do nothing. ${ }^{25}$ This explanation would look beyond the fact that many battered women married young, to consider the limited options open to working class girls: with wage rates, and the rules controlling access to housing, as they are, marriage and mother- $\frac{D}{0}$ hood are for many girls the only way of obtaining homes of their own and the adult status that goes $N$ with it. This explanation interprets the fact that $N$ many women do return to the husbands who assaulted them, not as a result of some sort of ${ }^{\mathrm{W}}$ sado-masochism, but as a consequence of the inadequate help given to battered women and the difficulties of life as a single parent family.

\section{Helping the battered women}

The research study which is the basis of this paper $\stackrel{\frac{\pi}{\Phi}}{\stackrel{2}{\Phi}}$ was carried out in a Women's Aid refuge in a $\varrho$ 
country town in South East England. Fifty women, all with children, were interviewed during their stay at the refuge, and are to be interviewed again some time after leaving the refuge: the great majority of the women were aged between 20 and 30 and most of their children were quite young: it is often when the children start to notice and to be distressed by what is happening between their parents that the mother decides that it is time to make a determined effort to leave. Most of the women had been physically assaulted for many years by the men with whom they lived, often since their first pregnancy or since the birth of their first child, and most had made previous attempts to leave home, usually going to friends or relatives. One section of the interview was concerned with these previous attempts to get help, and questions were included about the help the woman felt she had received from informal sources, such as her family, her friends and neighbours, and her husband's family, and from more official sources, such as doctors, health visitors, solicitors, social workers and the police. Thus the parts of the interviews concerned with the general practitioner comprised only a part of one section of the interviews.

It is important to emphasise how many-sided the problems of these women usually are. A women with a violent husband can hardly continue to live with him while divorce or separation proceedings are going through the courts; even getting an injunction to protect herself and her children may take many weeks. So if her husband will not leave the matrimonial home the woman herself will have to find other accommodation. She is likely to have many other problems; she may need medical care; she will almost certainly need a source of income; and often she will need protection in case her husband follows her and assaults her again. This problem is one reason why a woman often feels she cannot go to friends or relations; she has learnt from experience that her husband is likely to follow her and destroy the peace of the family which has given shelter to her and her children. Often a woman feels very ashamed of being battered and very confused about what she should do and what help she can expect, so she will need support and advice. Thus a great many agencies could, potentially, be in a position to help-the housing department, the social security office, the social services, the police, the legal profession, the medical profession, the marriage guidance council and others. It is perhaps the essence of this problem that, because it is potentially the concern of so many different people, it can so easily become the concern of nobodyexcept of the woman herself.

In many instances the general practitioner will be the first person, apart from family and friends, to hear about the problem. If the violence continues, it is likely that the general practitioner will also continue to be involved, since if the woman is to prosecute for assault, get an injunction to protect $\bar{c}$ herself, or apply for a divorce or separation using $\underset{\alpha}{\mathbb{D}}$ the violence as evidence, she will need a medical certificate to support her case. Thus it seems as though doctors will inevitably find themselves involved in the problems of battered women.

Some of the women visited their general practi- $\stackrel{\overrightarrow{\vec{F}}}{\stackrel{\overrightarrow{3}}{+}}$ tioner but did not mention this particular problem, often because they felt ashamed or because they did $\frac{\overline{\bar{O}}}{\bar{N}}$ not expect to meet with a sympathetic response. It $\frac{\bar{\rho}}{\vec{D}}$ may be that doctors should become more sensitive $\mathbb{Q}$ to the concealment of wife abuse, as they have become sensitive to the concealment of child abuse. Here is one woman, whose doctor was aware of this possibility but who still did not learn the truth:

On Valentine's Day he beat me up so muchcrawled up the stairs to Eve-I was near enough done in. He threw me across the room-he kept ${ }_{\omega}^{\circ}$ kneeing me in the gut. And I had great big bruises like that all over my body. When the doctor saw my $\vec{\nabla}$ bruises he said 'How did you get those,' And I saido to him 'I fell over'. And he said 'Are you sure,' and I said 'Yeah'

$Q$. Why couldn't you talk to him.

$A$. 'I don't know. I was embarrassed. It made me $\frac{\mathbb{D}}{3}$

feel I was in the wrong. You'd never expect ao battered wife to be in Broadstairs with all the old people'.

Another woman said of her doctor:

I didn't feel I could talk to him. They always see to rush you. So I used to say I'd fallen down stairs or that the wardrobe had fallen on me.

Sometimes doctors confirm the woman's feelings of $\stackrel{\mathbb{D}}{\stackrel{D}{2}}$ shame by their reaction to her:

When I called the police in they looked at me as though I was a slut. Because when you've been beaten about, and your hair is sticking up wild, and you've got a nightdress on because you've been $\overline{\widehat{B}}$ beaten up at 2 or 3 in the morning because your $\frac{}{\sigma}$ husband has walked in and decided to beat you up 3 . because he lost money gambling-when a woman is beaten up in a nightdress and the police come, it gives a bad impression. They don't realise that the $\mathrm{O}$ woman was woken up from her sleep. I've had the same attitude from doctors. I was taken in one $\frac{7}{0}$ morning at four o'clock and the doctor didn't even speak to me. He had to stitch me and take a nail out $N$ of my foot; I was in a state of shock and he never $N$ spoke to me-not at all. And of course my feet were N all black from running in the main road, and I had my night dress on, and I just thought-it gives the wrong impression.

Of the 50 women who were interviewed, 32 had $\stackrel{\overparen{D}}{?}$ talked to their general practitioner about their 0 marital problems and about the violent behaviour of the man with whom they were living. (By $\stackrel{\mathbb{Q}}{\square}$ comparison, 35 of the women had called in the $\stackrel{\mathbb{Q}}{Q}$ .

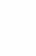


police at one time or another, and about $40 \mathrm{had}$ discussed their problems with a social worker). Of the women who had talked to a general practitioner, 18 ( 56 per cent) said that he or she had been either 'very helpful' or 'quite helpful'; I4 (44 per cent) said that he or she had not been helpful. The most frequent response of these 'unhelpful' general practitioners was the prescribing of anti-depressants and tranquillisers, most commonly Valium. One woman said of her doctor's use of Valium that 'he dishes them out like Smarties'; many of the women saw such treatment as an inappropriate, stop-gap measure which could well postpone their achievement of a satisfactory long-term solution.

Another source of dissatisfaction was the recognition that the wrong patient was in the consulting room. It was not possible to interview the men who had committed the assaults and so nothing can be said about their need for medical treatment; a few of the women mentioned that their husbands had received treatment at mental hospitals, but many more commented that their husbands perceived the violent behaviour as normal. Some general practitioners clearly considered the possibility that it might be more appropriate to treat the man than the woman, but recognising the impossibility of this, seemed to be unable to help the woman either. The following woman was echoed by many others when she said:

The doctor recommended psychiatric treatment for my husband-but I was much too frightened to tell him what the doctor had said:

\section{Another described how:}

I used to go to the Health Centre all black and blue, and my legs all black and blue and my knees all puffed up where he had kicked me. But they never bothered. They talked about it, but they didn't do anything to help.

$Q$. What sort of things did they say,

$A$. They just said 'Is he ill in any way, Does he need help ?' I think he does, with these tempers and that, because its not normal, bad tempers as violent as that. And I told them about his violent temper and they said they couldn't do nothing about it. Because they don't like to interfere.

Sometimes the husband would go to the doctor with his injured wife, so that she was unable to talk about how the injuries had occurred. As one said:

I couldn't talk to him about it. Well, when I used to go and see him usually John was with me anyway. He's very jealous like that, even though the doctor's an old man.

Other women were dissatisfied because the general practitioner's advice seemed to the women to be inappropriate, irrelevant or unsympathetic. One woman, whose husband was eventually judged by the court to be so violent that he was not allowed any access at all to the children said of her general practitioner:

My doctor said that he didn't want to appear for me. 吕 He'd seen a lot of the beatings and the bruisings, $\bar{\delta}$ but he didn't want to appear for me. My solicitor was going to force him, you know, sub poena him, $\stackrel{\vec{\rho}}{\stackrel{9}{+}}$ but my doctor's attitude was that I wanted to 0 change my husband and that I never would do, that I should learn to live more tolerantly with him.

Another woman said:

The doctor wasn't sympathetic at all. Actually I क wasn't looking for sympathy. I was wondering if he $\vec{\circ}$ could advise me of anywhere to go. And he just sort $\overrightarrow{\vec{\omega}}$ of said 'Take these tranquilisers and you'll be $\stackrel{\omega}{\omega}$ alright'. I said to him, I've come for help. I don't know who to go to but I read in many magazines $\overparen{D}$ that people go to their doctors'. I said this to him. ir And he asked me what was wrong, and I said, 'I'm feeling very depressed and I'm having a lot of $\vec{v}$ problems with my husband, and I would like some $ᄋ$ advice.' And he just wrote out a prescription and said 'Well, take these and you'll be alright'. He said of something like he hasn't got the time, or he's not $\frac{\mathbb{O}}{\mathbb{P}}$ paid to do what the Social Services should do'. So I $\frac{\mathbb{D}}{3}$ said 'Who are the Social Services,' And all he said $\frac{0}{0}$ was ' $G$ o to the Town Hall'. I sat down for two weeks and I thought 'Going to the Town Hall seems silly' $\vec{\oplus}$ One woman had talked to two different gener practitioners:

The first one I went to-I could have swung for him. He said 'What do you think this is-a bloody marriage guidance council,' He just wrote out the $\frac{\circ}{\Phi}$ prescription and that was it.

$Q$. A prescription for what?

A. Valium.

$Q$. And what did you talk to the other doctor about? I told him everything. He was so good, you know. He sat down and really listened. He said ' $\mathrm{I}$ think you'd be better off without your husband'. $\mathrm{He}^{\Phi}$ said 'Keep pushing the council for a place of your 3 own!'

General practitioners who were seen by the women as 'helpful' had many characteristics in common; the women described how these doctors $\square$ listened carefully, approached the problem sympathetically, offered appropriate advice, both N medical and non-medical, and so on. This 'good practice' could be summed up under three main $N$ headings:

I) Finding a solution to family and marital problems can take a long time, both in terms of the length of each session in the consulting room, and in terms of making decisions about divorce, reconcilia- + tion, or other possible solutions. One of the women $\frac{T}{\hat{O}}$ who was most enthusiastic about the helpfulness of $\frac{\mathrm{O}}{\mathrm{D}}$ her general practitioner described how he frequently $\frac{\mathcal{P}}{\mathbb{C}}$ arranged for her to have the last appointment of the 
surgery so that time should not be limited. In practices with attached social workers it may be appropriate to refer the patient to the practice social worker. ${ }^{26}$ However, there is a danger that the battered woman, with her many different problems, may get shunted from one agency of the welfare state to another, with no one agent prepared to take the time to consider her problems in their entirety; thus simply telling her to 'go to the Town Hall' may not be as helpful as spending a little longer in the consulting room.

2) The victims of marital violence may have medical symptoms but the most appropriate solutions in the long term will be non-medical: thus it is important that general practitioners be acquainted with some of the more relevant information. For example, it would be helpful to know the nearest women's refuge and how to get in contact with it. A crucial statute as far as battered women in England and Wales are concerned is the Domestic Violence and Matrimonial Proceedings Act of 1976, which made it easier for a woman to obtain an effective injunction against the man who assaulted her. The Housing (Homeless Persons) Act of 1977 laid on all Housing Departments in Britain the duty to offer temporary accommodation to woman with dependent children who have to leave home because of violence or threat of violence.

3) A general practitioner may well have to supply evidence about a woman's injuries, either in a court of law, or as evidence to the housing department of the woman's right to assistance under the Housing (Homeless Persons) Act. Lacking such evidence a woman may find herself being advised, in effect, to go home, get beaten again, and then present herself with the evidence of the beating. Careful records made on her first visit about the nature and extent of the injuries, even if not immediately useful, may in the long run save her additional suffering.

\section{Conclusion}

What, then are the limits to the responsibility of a general practitioner who is consulted by a woman who has been injured by the man with whom she lives ? Some general practitioners would argue that, while a woman's physical injuries were their responsibility, her wider problems could be dealt with more effectively by others; they might feel that it is largely inappropriate to suggest that battered woman should take their difficulties to the medical profession. Among the doctors interviewed by Cartwright, over half estimated that a quarter or more of their surgery consultations were for reasons they felt to be 'trivial, inappropriate or unnecessary'; of these consultations, 6 per cent involved some sort of emotional trouble, domestic anxiety, or personal inadequacy. ${ }^{27}$ Some general practitioners may have personal reasons for feeling reluctant to tackle such problems; others may see their role more in terms of

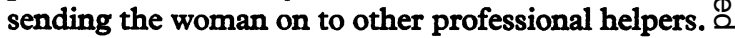

Nevertheless, because of their physical injuries, 制 battered women will continue to take their manysided problems to their doctors and will continue to ? hope that they may be helped. It seems that a new $\overrightarrow{\vec{F}}$ generation of general practitioners is coming $\frac{\text { ? }}{0}$ forward which is increasingly concerned about the profession's wider responsibility for the social $\overline{\frac{D}{D}}$ welfare problems of patients. Such a widening may $\overrightarrow{\widetilde{D}}$ have unforeseen implications, as Stimson pointed out in his article on 'Social care and the role of the general practitioner': 'adding a new feature to the $\vec{\circ}$ role of the general practitioner cannot be discussed without considering the more fundamental question $\vec{\omega}$ of the way we wish to tackle our medical and social problems.' 28 The problem of battered women $\overparen{\mathbb{D}}$ raises such issues in an unusually acute form. It is or impossible to separate the question of 'treatment' $\omega$ from wider questions, both about the nature of the $\overrightarrow{\vec{V}}$ problem itself, and about the nature of the general 0 practitioner's role. Whether marital violence is? 'explained' in terms of the individual, or the family, $\vec{c}$ or in terms of broader social patterns of inequality $\mathbb{D}$ must affect the way in which the general practitioner $\mathbb{D}$ approaches the problem. Similarly, whether the $\frac{3}{0}$ general practitioner defines his or her role narrowly $\mathbb{\mathbb { Q }}$ or broadly must affect the nature of the help which $\vec{\theta}$ is offered. Is the doctor responsible for the bruises, $v$ or for the patient? If the answer is that he or she responsible for the whole patient, the difficulty that, when the patient is a battered woman, medical treatment is usually only a small part of the help which is required.

\section{References}

${ }^{1}$ Royal College of General Practitioners (1972). The Future General Practitioner. Fournal of the royal college of general practitioners.

${ }^{2}$ Royal College of General Practitioners (1973). Present state and future needs of general practice. Fournal of $\frac{\Phi}{\square}$ the royal college of general practitioners.

${ }^{3}$ Central Statistical Office (1979). Social trends, No. 9. London. HMSO.

${ }^{4}$ Jefferys, M (1965). Anatomy of social welfare services. London. Michael Joseph.

${ }^{5}$ Ratoff, L \& Pearson, B (1970). Social casework in general practice: an alternative approach. British medical journal, 2, 475-477.

${ }^{6}$ Mayer, J E \& Timms, N (1970). The client speaks. N London. Routledge \& Kegan Paul. 'Rees, S (1978). Social work face to face. London. N
Arnold.

${ }^{8}$ This research study is being funded by the Department of Health and Social Security. The first part of the $\varphi$ study was completed in 1976 and published in $1978 \stackrel{\odot}{\odot}$ under the title $A$ refuge for battered women. A $\stackrel{?}{?}$ follow-up study, which is concerned with what $D$ happens to the women when they leave the refuge is to be completed in 1980 .

${ }^{\circ}$ Coote, A \& Gill, T (1977). Battered women and the $\frac{\odot}{\Phi}$ new law. National Council for Civil Liberties. 
${ }^{10}$ Pahl, J (1979). The control and allocation of money within the household. Unpublished paper.

"Pahl, J (1978). $A$ refuge for battered women. London. HMSO.

${ }^{12}$ Goode, W (197I). Force and violence in the Family. fournal of marriage and the family. 33, 24-8.

${ }^{13}$ Hammer, J (1977). Community action, women's aid and the women's liberation movement. In Women in the community, edited by M Mayo, London. Routledge and Kegan Paul.

${ }^{14} \mathrm{Jeffery}, \mathrm{L} \&$ Pahl, J (1979). Battered women and the police. Paper presented to the British Sociological Association Annual Conference.

${ }^{15}$ Dobash, R \& Dobash, R (1979). Violence against wives: a case against the patriarchy, New York. Free Press.

${ }^{16}$ Marsden, D (1978). Sociological perspectives on family violence. In Violence and the family. Edited by J Martin, Chichester. Wiley.

${ }^{17}$ Select Committee Report (1975). Violence in marriage, HCP. 1974-5 553, II.

${ }^{18}$ National Women's Aid Federation (1977). Battered women, refuges and women's aid.

${ }^{19}$ Faulk, M (1974). Men who assault their wives. Medicine, science and the law, $7,2$.

${ }^{20}$ Gelles, R (1972). The violent home, Sage, Beverley Hills.

${ }^{21}$ Moore, J (1977). Yo-yo children: a study of 23 M Roy. Van Nostrand Reinhold Company.

${ }^{22}$ Gayford, J J (1975). Wife battering: a preliminary survey of 100 cases. British medical journal, Vol. $x$.

${ }^{23} \mathrm{Goode}, \mathrm{W}$ J (1975) Force and violence in the family. In $\bar{\delta}$ Violence in the family. Edited by Steinmetz $S \&$ Straus M, New York. Dodd \& Mead.

${ }^{24}$ For a discussion of this analysis see, in particular, Freeman, M D (1979). Violence in the home, Saxon 당 House; Hammer, J (1978). Violence and the social $\frac{\bar{\omega}}{2}$ control of women. In Power and the state edited by $\vec{\nabla}$ G Littlejohn. Croom Helm; and Marsden, D op. cit. $\supseteq$ ${ }^{25}$ Dobash, $R$ \& Dobash, $R$ (1979). The Nature and Extent of Marital Violence. Paper presented to the $\vec{P}$ SCSS Conference on Violence in Marriage.

${ }^{26}$ For a discussion of the place of social work in general $\overrightarrow{\vec{H}}$ practice see Forman, J A S \& Fairbairn, E M (1968). $\mathscr{\omega}$ Social casework in general practice, Oxford University Press; Goldberg, E M \& Neill, J E (1972). Social work in general practice, Allen and Unwin; DHSS or (1974). Social work support for the health service, $\omega$ HMSO.

${ }^{27}$ Cartwright, A (1967). Patients and their doctors, 0 London. Routledge and Kegan Paul.

${ }^{28}$ Stimson, G V (1977). Social care and the role of the general practitioner. Social science and medicine, $11, \Phi$ $485-90$. 